[Agr. Biol. Chem., Vol. 30, No. 8, p. 770 778, 1966]

\title{
Separation of Soybean Sterols by Florisil Chromatography and Characterization of Acylated Steryl Glucoside*
}

\author{
By Toshiko Kiribuchi, Takemitsu Mizunaga and Saburo Funahashi \\ Department of Agricultural Chemistry, Faculty of Agriculture, \\ The University of Tokyo, Tokyo \\ Received February 15, 1966
}

\begin{abstract}
Florisil column chromatography was demonstrated to be effective in differentiation between different forms of sterols. Sterols of ground soybeans are in four forms, free, ester, and free and acylated glucosides, as analyzed on acetone extracts. In soybean oil foots, steryl ester is present in negligibly small amount. The acylated steryl glucosides were isolated from oil foots in a crystalline state. A chemical structure, steryl 6-acyl D-glucoside, was assigned to the compound, and its-probable identity with the glucosides reported by Lepage is discussed. The acylated glucoside preparation was shown to be heterogeneous in composition, carrying palmitic, stearic, oleic, linoleic and linolenic acids as the main acyl moieties and campesterol, stigmasterol and $\beta$-sitosterol as steryl moieties. The presence of the three sterols is common to three other forms of sterols.
\end{abstract}

Sterols has been known to exist in the vegetable kingdom in three different forms: free state, acyl ester and glycoside (phytosteroline). In the course of studies on soybean sterols in our laboratory, it became necessary to establish a systematic method for the fractional determination of the three forms. Chromatography on silicic acid has been widely used for separation of various classes of lipids since its introduction by Trappe in 1940.1,2) Recently, Florisil, an activated magnesium silicate, has been used with success as a supporting material for chromatography of neutral lipids by Carroll. ${ }^{3)}$ It is similar to silicic acid in adsorption characteristics for the class of neutral lipids. However, the strong adsorbing power of Florisil toward phospholipids seemed promising for use in the determination of sterols, particularly, for the purpose of separat-

\footnotetext{
* This work was supported by a PL 480 Research Grant from the Department of Agriculture, U.S.A., for the Project UR-A11(40) -13 .

1) W. Trappe, Biochem. $Z$., 306, 316 (1940).

2) W. Trappe, ibid,, 307, 97 (1941). (1961).
}

ing sterols from phospholipids, a group of major constituents in the extracts of oil seeds.

As a preliminary experiment to establish a systematic method for the analysis of naturally occurring sterols in soybeans, a mixture of cholesterol, cholesterol acetate and steryl glucoside was subjected to chromatographic separation on a Florisil column. The results obtained were satisfactory. Then we applied the method to a systematic analysis of sterols in the crude phosphatide fraction of soybeans (known as "foots") and in the acetone extracts of ground soybeans. In both cases, we found the presence of a considerable amount of an unknown form of sterol, which was characterized in this report as acylated steryl glucosides. Sterols in soybeans were thus demonstrated to exist in four different forms: free, ester, glucoside and acylated glucoside.

A preliminary report of a part of this work has been published.4)

\footnotetext{
4) T. Kiribuchi, C.S. Chen and S. Funahashi, This Journal 29, 265" (1965).
} 


\section{EXPERIMENTAL}

Materials. Florisil (60 100 mesh) was purchased from Floridin Co., U.S.A. The material was successively washed with methanol, ether, and $n$-hexane, dried, and deactivated with $6 \%$ of water.

Standard reference sterols. Commercial preparations of cholesterol, cholesterol acetate, $\beta$-sitosterol and stigmasterol were purified by two recrystallizations from ethanol. Campesterol was a generous gift from Dr. N. Ikekawa. Steryl glucoside was isolated from soybeans by the method of Aylward, ${ }^{5)}$ and purified by three precipitations from pyridine-95\% ethanol ( $1: 5$ ).

Soybean foots were supplied from Nisshin Oil Mills Co. and Nikka Fats and Oil Co., Ltd. The soybean sample used for sterol analyses is Hawkeye (U.S.A.) variety purchased in the market.

Extraction of Soybean Sterols. Pulverized soybean was extracted with acetone in a Soxhlet apparatus for 20 hours at $85^{\circ} \mathrm{C}^{*}$. The acetone was distilled off under reduced pressure and the residual oil was subjected to analyses as crude sterols.

Chromatographic Methods. For chromatography, $10 \mathrm{~g}$ of Florisil was packed in a chromatographic tube $(1.0 \mathrm{~cm} \times 40 \mathrm{~cm})$. A sterol mixture dissolved in a small volume of hexane was then placed on the column. Steryl glucosides which were insoluble in hexane were placed on the column as a turbid suspension. Elution was carried out as described later for individual experiments. The eluate from the column was collected in $8 \mathrm{ml}$ fractions. Sterols in individual fractions were determined by the methods which will be described below.

For thin-layer chromatography (TLC), glass plates $(10 \mathrm{~cm} \times 20 \mathrm{~cm}$ or $20 \mathrm{~cm} \times 20 \mathrm{~cm})$ were coated with Silica Gel G (prepared according to Stahl, E. Merck, Germany) and dried in an oven at $120^{\circ} \mathrm{C}$ for 2 hours. The plate was spotted with the sterol mixture, and developed with either chloroform-methanol-acetic acidwater $(90: 8: 1: 1)$ or benzene-ethyl acetate $(5: 1)$. Sterols were detected on the plate by spraying with concentrated sulfuric acid and heating at $110^{\circ} \mathrm{C}$ for 10 minutes.

The sterols were analyzed by gas-liquid chromatoรraphy (GLC) on a $2.25 \mathrm{~m}$ stainless steel column of liameter $4 \mathrm{~mm}$, packed with $1.5 \%$ silicone $\mathrm{SE}-30$

\footnotetext{
5) F. Aylward, Nature, 181, 1064 (1958).

* We tested hexane, acetone and $80 \%$ ethanol as solvents. the use of acetone under the condition proved to be most effiient for extraction of sterols from soybeans, giving as much as $8 \%$ yield by a single 20 hours treatment.
}

coated on $60 \sim 80$ mesh chromosorb $W$. The instrument used was the Shimadzu GC-1B, equipped with hydrogen flame ionization detector. The column was maintained at $240^{\circ} \mathrm{C}$, and the flow rate of nitrogen was $30 \mathrm{ml}$ per minute. Individual sterols were identified by comparing relative retention times of the samples with those of authentic sterols.

Fatty acid methyl esters were analyzed by GLC. A stainless steel column $(1.5 \mathrm{~m} \times 4 \mathrm{~mm})$ packed with $20 \%$ polyethylene glycol adipate (prepared by synthesis $^{6)}$ ) adsorbed on $80 \sim 100$ mesh Shimalite $C$ was employed for this separation. The temperature of the column was maintained at $190^{\circ} \mathrm{C}$, and the flow rate of nitrogen was $40 \mathrm{ml}$ per minute. Individual fatty acids were identified from the relative retention times obtained for authentic fatty acids.

Assay of Sterols. Steryl glucosides and their acylated form were determined essentially by Momose's method $^{7)}$ with slight modifications. To $4 \mathrm{ml}$ of a sterol solution in glacial acetic acid, $2 \mathrm{ml}$ of color reagent was added and the mixture was kept for 20 minutes in a boiling water-bath. Optical density at $430 \mathrm{~m}_{\mu}$ was measured on the cooled solution and the sterol concentration was determined from a standard curve prepared with authentic stigmasterol. The color reagent contained $200 \mathrm{ml}$ of $70 \%$ perchloric acid, $600 \mathrm{ml}$ of $85 \%$ orthophosphoric acid, and $16 \mathrm{~g}$ of ferric chloride.

Liebermann-Burchard reaction was used for the assay of free and ester forms as follows: $2 \mathrm{ml}$ of acetic anhydride was added to $2 \mathrm{ml}$ of the test solution in chloroform. Two drops of concentrated sulfuric acid were then added to the mixture and it was kept standing exactly for 30 minutes. Colorimetry was made at $655 \mathrm{~m}_{\mu}$ and the sterol content estimated from a standard curve for $\beta$-sitosterol.

\section{RESULTS}

\section{Separation of Various Forms of Sterols on Florisil} Columns.

1) Separation of cholesteryl ester, free cholesterol and steryl glucosides. A mixture of cholesteryl acetate, free cholesterol and soybean steryl glucosides was subjected to the Florisil column chromatography by stepwise elution as illustrated in Fig. $\mathbf{I}$. The eluting

6) A.T. James, "Methods of Biochemical Analysis", ed. by David Glick, Interscience publishers, Inc., Vol. VIII, p. 10 (1960). 7) T. Momose, Y. Ueda and K. Yamamoto, Anal. Chem., 35, 1751 (1963) 


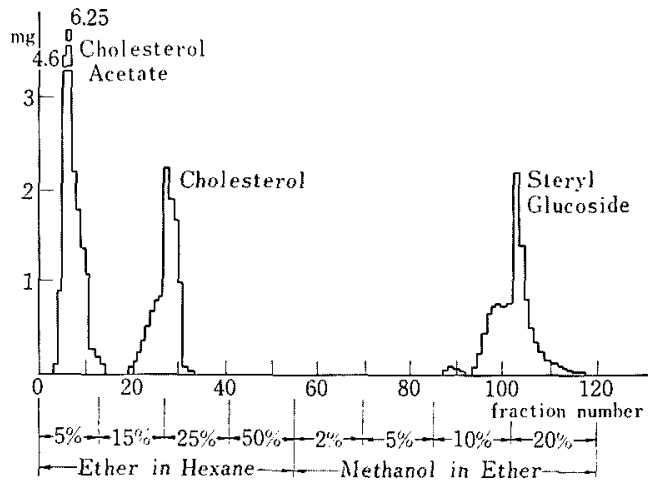

Fig. 1. Separation of a Sterol Mixture on Florisil Column by Stepwise Elution Method.

$5 \mathrm{ml}$ fractions were collected. The column load consisted of a mixture of $21.9 \mathrm{mg}$ cholesteryl acetate, $11.2 \mathrm{mg}$ cholesterol and $17.4 \mathrm{mg}$ steryl glucoside.

Table I. Elution Schedul,es for FLoRISIL Chromatograms

Sterols Eluted

Cholesteryl acetate Free cholesterol

Steryl glucoside

\section{Eluting Solvent}

$5 \%$ ether in hexane* $50 \mathrm{ml}$ $15 \%$ ether in hexane $80 \mathrm{ml}$ $25 \%$ ether in hexane $80 \mathrm{ml}$ $50 \%$ ether in hexane $80 \mathrm{ml}$ $2 \%$ methanol in ether $100 \mathrm{ml}$ $5 \%$ methanol in ether $100 \mathrm{ml}$ $10 \%$ methanol in ether $100 \mathrm{ml}$ $20 \%$ methanol in ether $100 \mathrm{ml}$ $30 \%$ methanol in ether $100 \mathrm{ml}$

* $n$-hexane: b.p. $64 \sim 66^{\circ} \mathrm{C}$.

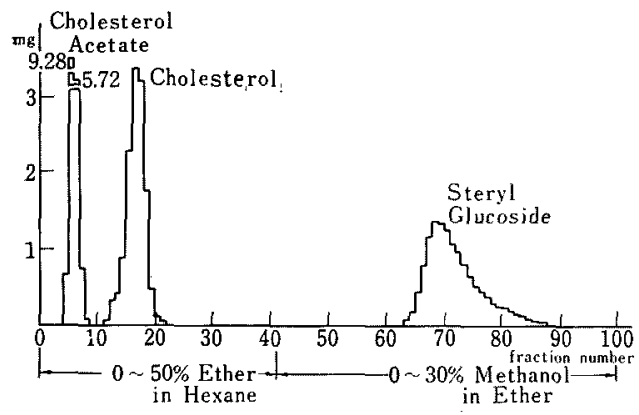

FiG. 2. Separation of a Sterol Mixture on Florisil Column by Linear Gradient Elution Method.

Two solvent systems as specified in the figure. $8 \mathrm{ml}$ fractions were collected. The sample consisted of $16.4 \mathrm{mg}$ cholesteryl acetate, $13.1 \mathrm{mg}$ cholesterol and $18.6 \mathrm{mg}$ steryl glucoside. solvents used are shown in Table I. In another experiment gradient elution systems. were tried. The column was eluted first with a linear gradient of ether from zero to fifty per cent in hexane, and then with a linear gradient of methanol from zero to thirty per cent in ether, giving a better result than the stepwise elution method (Fig. 2). The three different forms of sterols were found to be satisfactorily separated, since they were shown to be homogeneous by TLC. The recovery of reference sterols from the Florisil column was always in the range from $95 \%$ to $105 \%$.

2) Separation of various forms of sterol in soybean foots and ground soybeans. Sterols in soybean oil foots were chromatographed on a Florisil column by the gradient elution method as described above. However, a marked contamination of steryl glucoside fraction with phospholipids was observed. In the subsequent work the trouble was overcome by a preliminary fractionation of "foots" as follows: about $300 \mathrm{mg}$ of "foots" dissolved in a small volume of hexane was placed on a $10 \mathrm{~g}$ Florisil column, followed by elution with $250 \mathrm{ml}$ of $30 \%$ methanol in diethyl ether. The eluate containing a lesser amount of phospholipids was subjected to the second column chromato-

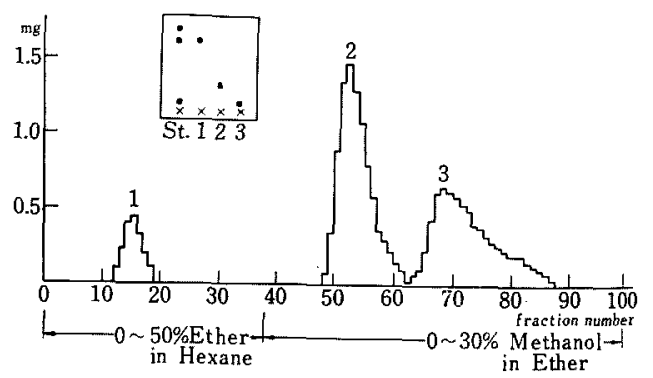

Fig. 3. Separation of Sterols in Oil Foots on Florisil Column.

$343 \mathrm{mg}$ of foots were chromatographed on Florisil column $(12 \mathrm{~g})$ by the gradient elution. The foots were preliminarily fractionated on Florisil column to minimize the phospholipids content. $8 \mathrm{ml}$ fractions were collected. A thin-layer chromatogram is also shown. Developing solvent: chloroform-methanolacetic acid-water (90:8:1:1). From left to right: standard mikture (from top to bottom: $\beta$-sitosterol acetate, $\beta$-sitostero steryl glucoside), fraction 1, fraction, 2, fraction 3 . 
Table II. Analyses of Sterols in Soybean Foots Separated on is Florisil Column

\begin{tabular}{|c|c|c|c|c|c|}
\hline & \multicolumn{2}{|c|}{$\begin{array}{c}\text { (A) Without preliminary } \\
\text { fractionation } \\
\text { (300 } \mathrm{mg} \text { of foots })\end{array}$} & \multicolumn{2}{|c|}{$\begin{array}{c}\text { (B) After preliminary } \\
\text { fractionation } \\
\text { (343 mg of foots) }\end{array}$} & (B) $/(\mathrm{A})$ \\
\hline & $m g^{*}$ & $\%$ & $\mathrm{mg}^{*}$ & $\%$ & $\%$ \\
\hline Free sterol & 1.60 & 0.53 & 1.75 & 0.51 & 96.3 \\
\hline Acylated steryl glucoside & 7.96 & 2.65 & 8.92 & 2.6 & 98.2 \\
\hline Steryl glucoside & 6.47 & 2.22 & 7.12 & 2.1 & 95.0 \\
\hline Total sterol & 16.03 & 5.35 & 17.79 & 5.2 & 97.0 \\
\hline
\end{tabular}

graphy. The chromatography effected a good separation to three peaks which were demonstrated to correspond to free sterols, and free and acylated steryl glucosides by TLC (Fig. 3). The peak attributable to the ester form was negligibly small. Determination of sterols in the individual fractions gave the results shown in Table II.

The same chromatography of a sterol mixture extracted from ground soybeans $(22 \mathrm{~g})$ with acetone for 20 hours gave four sterolpositive fractions corresponding to steryl ester*, free sterols, and free and acylated steryl glucosides (Fig. 4), in the amount of $8.79 \mathrm{mg}$

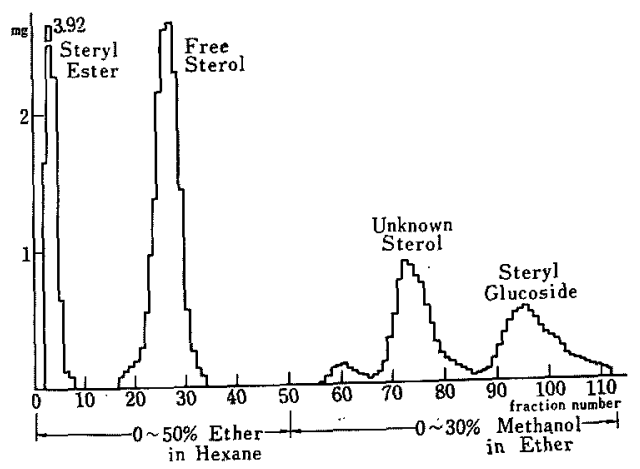

Fig. 4. Fractionation of Soybean Sterols into Four Forms on Florisil Column.

Acetone extract of ground soybeans $(22 \mathrm{~g})$ was preliminarily fractionated and chromatographed on Florisil column $(20 \mathrm{~g})$ by the gradient elution method. $8 \mathrm{ml}$ fractions were collected.

* We wish to mention that, in the previous experiments4, the steryl ester escaped detection due to its quick elution by hexane at the stage of preliminary chromatography designed for elimination of phospholipids. Revised chromatographic procedure is described in this paper.
(0.044\%), $16.04 \mathrm{mg}(0.081 \%), 7.43 \mathrm{mg}(0.037 \%)$ and $6.6 \mathrm{mg}(0.033 \%)$, respectively, as calculated on the basis of $\beta$-sitosterol or stigmasterol, and expressed as per cent of the ground soybeans.

\section{Identification of Sterols.}

1) Free sterols. Fractions containing free sterols (peak 1 in Fig. 3) were combined and solvents were evaporated in vacuo. The residue was crystallized from acetone, and colorless crystals obtained had a m.p.136.0 136.5 ${ }^{\circ} \mathrm{C}$, $[\alpha]_{\mathrm{D}}^{20}-38.8^{\circ}(c=2.32$, chloroform). The infrared spectra of the purified sterols are shown in Fig. 5B. The gas chromatographic analysis of free sterol fractions of oil foots gave three peaks (Fig. 6), which were identified as campesterol, stigmasterol and $\beta$-sitosterol, their relative retention times being $0.91,0.99$ and 1.14, respectively, based on that of stigmasterol; those for authentic campesterol, stigmasterol and $\beta$-sitosterol were $0.92,1.00$ and 1.14, respectively. A quantitative measurement of peak areas on the gas chromatogram gave the following results: campesterol, $21.2 \%$, stigmasterol, $30.4 \%$, and $\beta$-sitosterol, $48.5 \%$.

2) Steryl glucosides. The third fractions. in Fig. 3 were combined and evaporated to dryness. The residue was purified by repeated precipitation from pyridine-95\% ethanol and the colorless solid obtained showed positive Liebermann-Burchard and Molisch tests; m.p. $273 \sim 276^{\circ} \mathrm{C}$ (decomp.). $[\alpha]_{\mathrm{D}}^{20}$ $-46.4^{\circ} \quad(c=1$, pyridine). These values correspond with those reported by other work- 


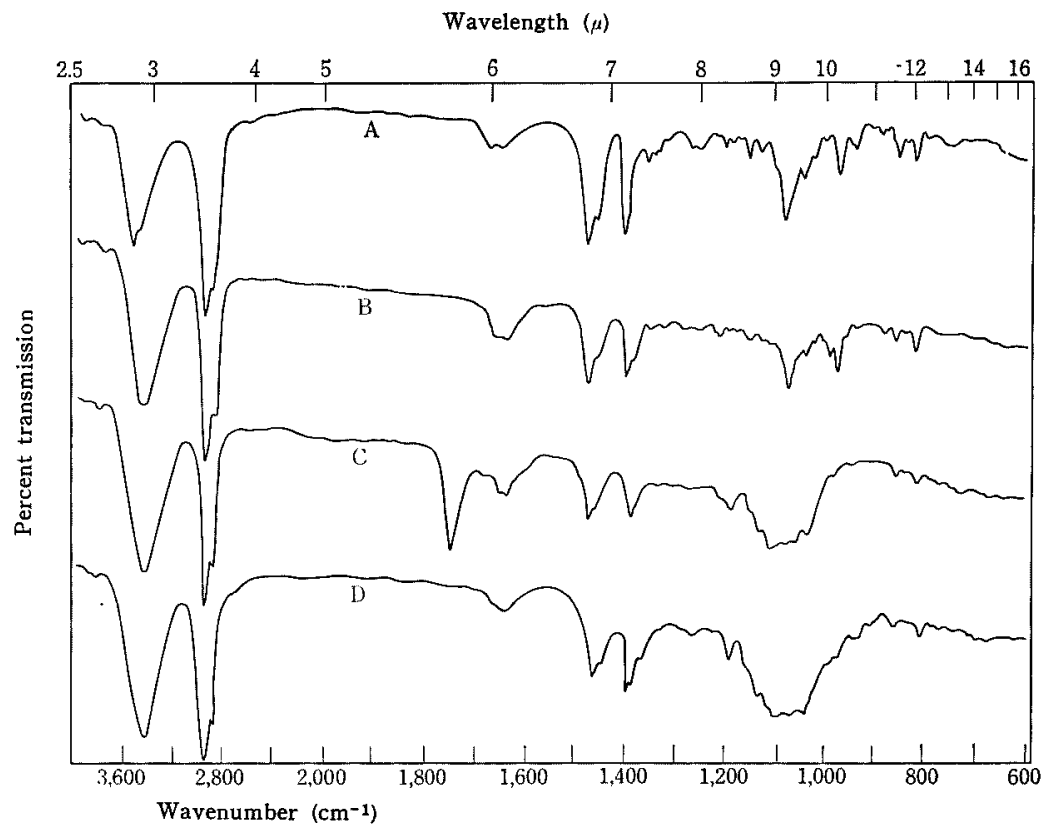

Fig. 5. Infrared Absorption Spectra.

Authentic $\beta$-sitosterol (A), free sterols isolated from soybean foots (B), acylated steryl glucoside (C) and steryl glucosides isolated from soybean foots (D) were recorded using potassium bromide disks.

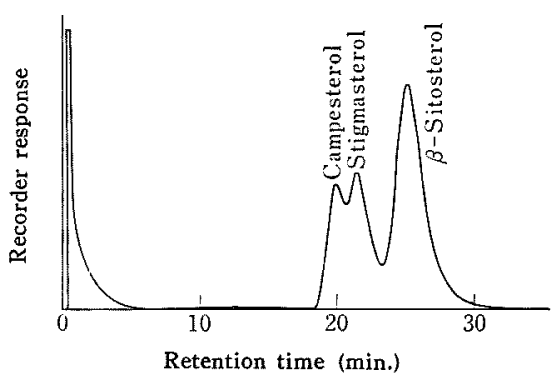

Fic. 6. Gas Chromatogram of Sterols in Soybean Foots.

The sterols were chromatographed on chromosorb W $\left(60-80\right.$ mesh) coated with $1.5 \% \mathrm{SE} \cdot 30$, at $240^{\circ} \mathrm{C}$ and a nitrogen flow.rate of $30 \mathrm{ml}$ per minute, by using a hydrogen flame ionization detector.

ers $^{\overline{5}, 8}$ 10) on steryl glucosides. The infrared absorption spectrum of the material (Fig. 5D)

8) L.J. Swift, J. Amer. Chem. Soc., 74, 1099 (1952).

9) R.M. Ma and P.S. Schaffer, Arch. Biochem. Biophys., 47, 419 (1953).

10) A.G. Kallianos, F.A. Shelburne, R.E. Means, R.D. Stevens, R.E. Lax and I.D. Mold, Biochem. J., 87, 596 (1963). is in good agreement with that reported by Morris and Lee ${ }^{11)}$ for $\beta$-sitosterol-D-glucoside with a broad $\mathrm{OH}$-group absorption at 3440 $\mathrm{cm}^{-1}$, a $-\mathrm{CH}_{2^{-}}$absorption at 2940 and 2860 $\mathrm{cm}^{-1}$, and a broad absorption in the region of $1125 \sim 1000 \mathrm{~cm}^{-1}$ characteristic of sugar. Steryl glycosides, when hydrolyzed with sulfuric acid in ethanol by the method of Thornton and his co-workers, ${ }^{12}$ ) gave sterols and reducing sugars in equimolar amounts, as determined by the ferric chloride-perchloric acid and phenol-sulfuric acid reactions, respectively. The sugar component was tentatively identified as D-glucose by paper chromatography using $n$-butanol-acetic acid-water $(4: 1: 5)$, $9 \%$ phenol, or $n$-butanol-pyridine-water ( 3 : $2: 1.5)$ as the solvents and aniline hydrogen phthalate as the spray reagent. A further (11) M.J. Morris and L.S. Lee, J. Agr. Food Chem., 9, 401

12) M.H. Thornton, H.R. Kraybill and J.H. Mitchell, J. Amer. Chem. Soc., 62, $2006(1940)$. 

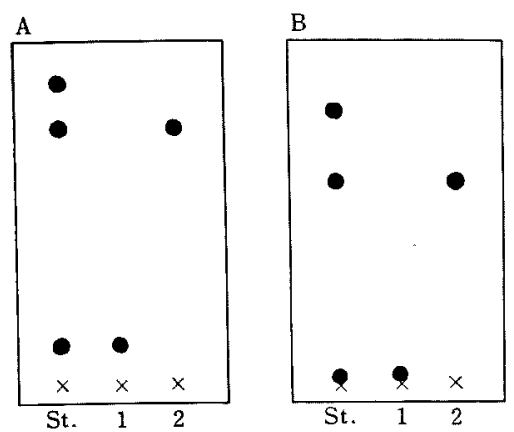

Fig. 7. Thin-layer Chromatograms of Sterol Component in the Hydrolyzate of Steryl Glucoside.

Solvent systems: for plate A, chloroform-methanolacetic acid-water (90:8:1:1); for plate B, chloroformmethanol (95:5). From left to right: St., standard mixture (from top to bottom, $\beta$-sitosteryl acetate, $\beta$ sitosterol, steryl glucoside); 1 , steryl glucosides; 2 , sterol components of the acid hydrolyzate of steryl glucosides.

confirmation was made by osazone formation: m.p. $204^{\circ} \mathrm{C}$. The sterol fraction of the hydrolyzate was subjected to TLC (Fig. 7) and GLC. The gas chromatogram revealed three peaks which could be assigned to campesterol, stigmasterol and $\beta$-sitosterol by their relative retention times as mentioned above; their contents were $20.0,29.4$ and $50.6 \%$, respectively. These results indicate that the steryl glycosides isolated from soybean foots are a mixture of D-glucosides of campesterol, stigmasterol and $\beta$-sitosterol.

Characterization and Structural Determination of the Acylated Steryl Glucosides

The acylated steryl glucoside fractions obtained from ten batches of eluate from the Florisil chromatography of the acetone extracts of soybean oil foots were combined to yield $4.68 \mathrm{~g}$ of the crude preparation. After five recrystallizations from acetone, $2.83 \mathrm{~g}$ of colorless crystalline plates were obtained.

1) Properties. The material, after several crystallizations from acetone, gave colorless crystals; m.p. $130 \sim 150^{\circ} \mathrm{C}, \quad[\alpha]_{\mathrm{D}}^{20}-25.5^{\circ} \quad(c=$ 0.94, pyridine). Anal. Found: C, 75.21; H,
10.86. Calcd. for $\mathrm{C}_{53} \mathrm{H}_{94} \mathrm{O}_{7}: \mathrm{C}, 75.48 ; \mathrm{H}$, $11.23 \%$. The crystalline product was hygroscopic and readily soluble in pyridine and ether, slightly soluble in chloroform, and insoluble in other organic solvents. It gave positive tests for Liebermann-Burchard, Molisch, and hydroxamic acid reactions indicating the presence of sterol, sugar and esterlinkage, respectively. It gave, however, negative test for phosphorus, nitrogen and sulfur. Negative test with lead tetraacetate in benzene solution ${ }^{13)}$ indicates the absence of a monoglyceride which is expected to appear, if present, in the same fraction from the Florisil chromatography under the conditions employed. The infrared absorption spectrum of the acylated steryl glucosides (recorded in a potassium bromide disk) (Fig. 5C) was very similar to that of steryl glucosides (Fig. 5D) except that the latter lacked the very strong $\mathrm{C}=\mathrm{O}$ absorption at $1740 \mathrm{~cm}^{-1}$. These characteristics and the chromatographic behavior of

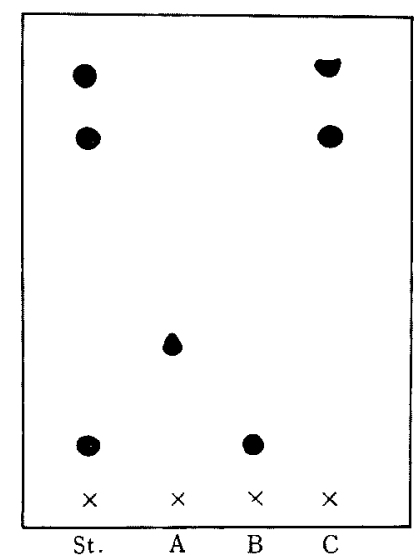

FIG. 8. Thin-layer Chromatogram of Sterol Components in the Hydrolyzate of Acylated Steryl Glucoside.

Solvent system: chloroform-methanol-acetic acid-water (90:8:1:1). St.: authentic samples (from top to bottom, $\beta$-sitosteryl acetate, $\beta$ sitosterol, and steryl glucoside); A, acylated steryl glucoside; $\mathrm{B}$, alkaline hydrolyzate; $\mathrm{C}$, acid hydrolyzate.

13) H.K. Mangold, B.G. Lang and H. Schlenk, J. Amer. Chem. Soc., 77,6070 (1955). 


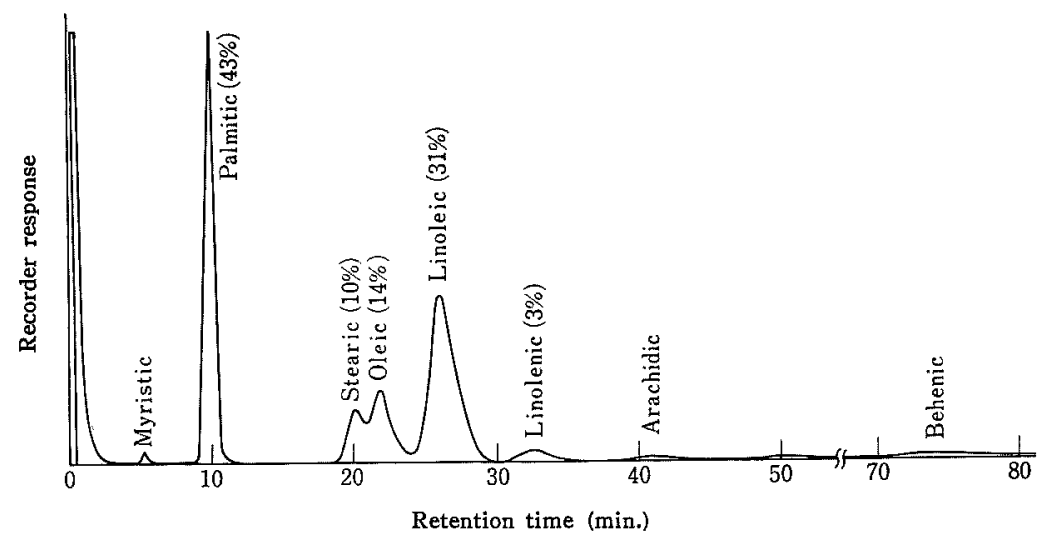

Fic. 9. Gas Chromatogram of Fatty Acid Components of Acylated Steryl Glucoside.

The fatty acid methyl esters were chromatographed on Shimalite C (80 100 mesh) coated with $20 \%$ polyethylene glycol adipate, at $190^{\circ} \mathrm{C}$ and a nitrogen flow rate of $40 \mathrm{ml}$ per minute, by using a hydrogen flame ionization detector.

the sample strongly suggest that it is an acylated form of steryl glucoside.

2) Alkaline hydrolysis of the acylated steryl glucosides. The crystalline acylated steryl glucosides (100 mg) were hydrolyzed in $10 \mathrm{ml}$ of $10 \%$ alcoholic potassium hydroxide solution for 4 hours at $95^{\circ} \mathrm{C}$. Water and diethyl ether were added to the digest and fluffy layer, produced at the interface, was collected. The substance gave a single spot on TLC (Fig. 8B), and a single peak as well on the Florisil column chromatogram, which was identified as steryl glucosides. The steryl glucosides thus obtained were nonreducing and exhibited the same infrared absorption spectrum as that of steryl glucosides as described earlier. By acidification of the aqueous layer of the alkaline hydrolyzate, an acid substance was obtained. Its methyl ester was analyzed by GLC, and identified as mixed fatty acid esters. As shown in Fig. 9, palmitic $(42.7 \%)$, stearic $(9.6 \%)$, oleic $(13.7 \%)$, linoleic $(31.2 \%)$, and linolenic $(2.8 \%)$ acids were the main fatty acids. A trace of myristic, arachidic and behenic acids were also present. These results indicate that fatty acyl residues are bound to steryl glucosides by an ester linkage.
3) Acid hydrolysis. $100 \mathrm{mg}$ of the acylated steryl glucosides was hydrolyzed in $10 \mathrm{ml}$ of absolute ethanol containing $0.1 \mathrm{ml}$ of concentrated sulfuric acid under reflux for 22 hours

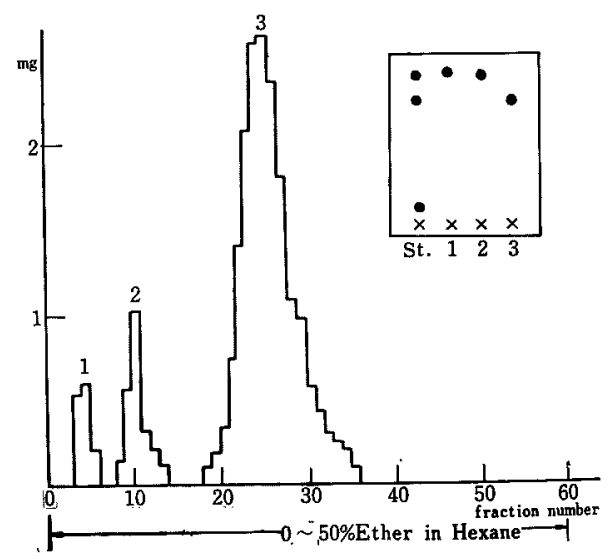

FIG. 10. Florisil Column Chromatogram of Ethersoluble Fraction of Acid Hydrolyzate of Acylated, Glucosides, and Thin-layer Chromatogram of the Fractions Obtained.

$12 \mathrm{~g}$ of Florisil were used, and $5 \mathrm{ml}$ fractions were collected. Thin-layer chromatography of these fractions was effected with Silica Gel G. Developing solvent: chloroformmethanol-acetic acid-water (90:8:1:1). From left to right:" st., standard mixture (from top to bottom, B-sitosterol acetate, $\beta$-sitosterol, steryl glucoside); 1,2 , and 3 , Fractions 1,2 , and 3 , respectively. 
by the method of Thornton et al.12) Ethanol was distilled off under reduced pressure and a small amount of water was added to the residue. The suspension was extracted repeatedly with ether. The ether extracts gave three fractions on Florisil column chromatography as shown in Fig. 10. Fraction 3, the main product (about $84 \%$ ) of acid hydrolysis, was shown by TLC to contain only free sterols. Fractions 1 and 2 gave the same $R_{F}$ value as that of authentic $\beta$-sitosteryl acetate on TLC. However, these products were found to be formed when free $\beta$-sitosterol was heated under the same conditions, indicating the products to be artifacts formed during acid treatment. GLC of Fraction 3 showed that the free sterol mixture was composed of campesterol, stigmasterol and $\beta$-sitosterol at a ratio of 20, 29 and 51. The residual aqueous layer after ether extraction reduced Fehling's solution. Sulfate ion was removed as barium salt and the filtrate was subjected to paper chromatography. By use of three solvent systems described earlier and aniline hydrogen phthalate for the detection of sugar, the reducing material was identified as D-glucose.

4) Molar ratio of the components in the acylated steryl glucosides. The results obtained by alkaline and acid hydrolyses of the acylated steryl glucosides indicate that they are composed of sterols, glucose and fatty acids. For quantitative determination of these components, sterols and glucose were assayed on acid hydrolyzate by ferric chloride-perchloric acid reaction and phenol-sulfuric acid reaction, respectively. Ester linkage was determined colorimetrically by hydroxamate formation, and fatty acids were assayed on alkaline hydrolyzate by alkali titration. The molar ratio $1: 0.85: 0.97: 0.90$ thus obtained for sterols, glucose, ester linkage and acids indicates that the acylated steryl glucosides are composed of sterols, glucose and fatty acids at an equivalent ratio.
5) Periodate oxidation. $60 \mu$ moles of acylated steryl glucosides were oxidized with $1600 \mu$ moles of sodium periodate in $50 \%$ aqueous acetone at $20^{\circ} \mathrm{C}$ in the dark by the method of Dyer,14) and the periodate consumed and the acid liberated were determined. After about 30 hours, 1.995 moles of periodate were consumed and 1.02 moles of formic acid were produced per mole of the acylated steryl glucosides. The result demonstrates that fatty acyl residue is linked to $\mathrm{C}-6$ of the glucose moiety, and excludes the possible ester linkage at $\mathrm{C}-2,-3$, or -4 .

On the basis of these results, a steryl 6-acylD-glucoside structure was assigned to the glucosides. As can be seen from the analyses of component fatty acids and sterols described above, the acyl steryl glucoside preparation isolated from soybean oil foots is heterogeneous in composition containing either campesterol, stigmasterol or $\beta$-sitosterol as sterol moiety, and either palmitic, stearic, oleic, linoleic or linolenic acid as fatty acyl residue.

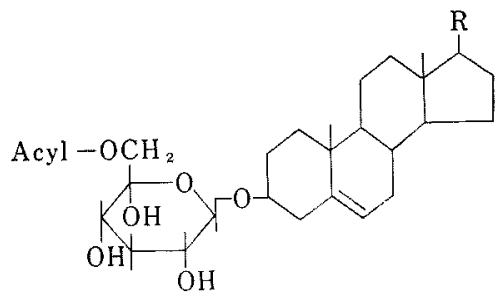

Steryl 6-acyl-D-glucoside

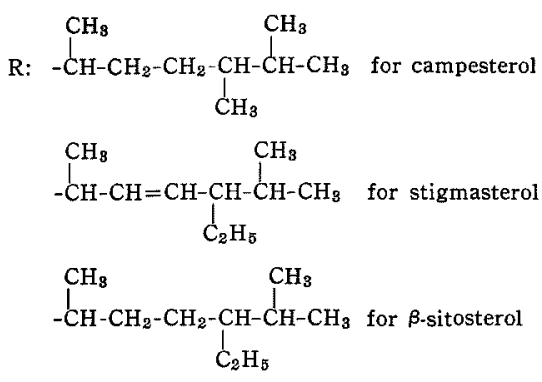

14) J.R. Dyer, "Methods of Biachemical Analysis", ed. by Dayid Glick, Interscience Publishers, Inc., Vol. III, p. 11 (1956). 


\section{DISCUSSION}

The chromatographic method on a Florisil column proved to be effective in the quantitative separation of soybean sterols into four different forms. When the method was applied in combination with gas-liquid chromatography to oil seeds such as soybeans used in the present investigation, it enables us to fractionate sterols into free, ester, glucoside, and acylated glucoside forms, and to determine the sterol composition of each fraction without difficulty. Application of the Florisil column chromatography to sterol mixtures extracted from various oil seeds indicated that this method was applicable as a general method to fractionation of plant sterols, as described in our preliminary report.4)

The presence of campesterol glucoside in soybean foots was not reported before. Our finding that campesterol, stigmasterol and $\beta$ sitosterol were the components of glucoside as well as those of other forms of soybean sterols is of interest in view of the recent report by Kallianos et al., ${ }^{10)}$ who isolated a mixture of glucosides of the same three sterols from a commercial blend of flue-cured Burley, Maryland and Turkish tobaccos and from the smoke of cigarettes manufactured from the same blend of tobaccos.

A new type of plant sterol was isolated by the Florisil column chromatography of soybean sterol and its structure was established as steryl 6-acyl-D-glucoside in which sterols are attached to C-1 and fatty acyl residue to C-6 of the glucose moiety. The sterol components were campesterol, stigmasterol and $\beta$-sitosterol as found in other forms of sterols.

Our attempts to determine the anomeric form of its glucosidic linkage with a $\beta$-glucosidase preparation are so far unsuccessful. However, in view of the fact that a number of naturally occurring glycosides are of $\beta$ glycosidic linkage, our steryl glucoside, free and acylated, may also be of the $\beta$-configuration.

Recently, Lepage has reported the isolation and characterization of an esterified form of steryl glucoside from potato tuber lipids and soybean phosphatides, and assigned the steryl 6-acyl-D-glucoside structure to the lipids. ${ }^{15}$ ) The Lepage's compound is most probably identical with ours. He stated that the lipid was identified in a variety of plant tissues: potato leaves and tubers, peas, soybeans, alfalfa, and wheat. Our findings that the acyl steryl glucoside is distributed in all oil seeds examined,4) including peanuts, and sesame, castor bean, rape, cotton, and safflower seeds, and mung bean and soybean seedlings*, may provide a further support to his view that the compound is widely distributed in the vegetable kingdom.

Acknowledgements. The authors wish to thank Dr. N. Ikekawa of Institute of Physical and Chemical Research for the gift of authentic campesterol, Mr. K. Aizawa for infrared spectra, and Nisshin Oil Mills Co. and Nikka Fats and Oil Co., Ltd., for supplying the soybean foots.

15) M. Lepage, J. Lipid Res., 5, 587 (1964).

* unpublished data. 